\title{
2-methylbutyryl-CoA dehydrogenase deficiency
}

INSERM

\section{Source}

INSERM. (1999). Orphanet: an online rare disease and orphan drug data base. $\underline{2-}$ methylbutyryl-COA dehydrogenase deficiency. ORPHA:79157

2-Methylbutyryl-CoA dehydrogenase (or Short/branched-chain acyl-coA dehydrogenase; SBCAD) deficiency is characterized by increased urinary excretion of 2 -

methylbutyrylglycine, and increased whole blood and plasma concentrations of 2methylbutyryl (C5) carnitine. It has been described in less than 30 patients, mostly from the Hmong population, an ethnic group of Chinese origin. The phenotype is not well defined, ranging from completely asymptomatic patients to those with muscle hypotonia, cerebral palsy, developmental delay, lethargy, hypoglycemia, and metabolic acidosis. The disorder is transmitted as an autosomal recessive trait. The SBCAD enzyme catalyzes the conversion of 2-methylbutyryl-CoA to tiglyl-CoA in the isoleucine catabolic pathway. Mutations in the SBCAD gene (located on chromosome 10q25-26) have been reported in affected patients. Treatment includes carnitine supplementation and a low-protein diet. 